\title{
VALUE OF CHARACTER EDUCATION IN 1 AMBEUA PRIMARY SCHOOL STUDENTS
}

\author{
FELTA \\ Program Studi Sastra Indonesia \\ Fakultas Ilmu Budaya, Universitas Halu Oleo
}

\begin{abstract}
This study aims to describe the values of character education in SDN 1 Ambeua students. This research is a qualitative research with a phenomenological approach. Data were collected using the observation method with moderate participatory observation techniques, recording techniques, and note taking techniques. Data were analyzed descriptively in accordance with the theory of the application of character education by Lickona and Amirulloh.

The results of the study prove that the application of character education values to students of SDN 1 Ambeua is moral knowledge, including moral awareness; knowledge of moral values; understand the other person's point of view; moral reasoning; courage to make decisions; self introduction (Self Knowledge). Moral feelings include listening to conscience; self-esteem (self esteem); empathy; love of kindness; self control; humility. Moral action includes competence (competence); desire (will); habit.

Keywords: values, education, character, students, ambeua
\end{abstract}




\section{PENDAHULUAN}

Pendidikan karakter adalah hal yang paling krusial dalam dunia pendidikan. Pendidikan ini adalah pilar yang menentukan apakah pendidikan dapat bermanfaat atau justru menjadi malapetaka bagi umat manusia.Hal yang paling ditakuti guru bukanlah siswa yang tidak mampu mengikuti pelajaran matematika atau pelajaran rumit lainnya. Guru lebih khawatir jika siswa tidak dapat belajar mengantre.

Ketika siswa mampu mengantre, berarti siswa telah mempelajari konsekuensi dari persiapan yang kurang matang, yakni nomor antrean belakang. Sebaliknya, jika mereka sudah datang lebih dulu, mereka akan mendapatkan nomor antrean lebih awal. Mengantre juga memberikan pelajaran menghargai sistem, hak orang lain, disiplin diri dan konsekuen terhadap perbuatannya sendiri.

Karakter adalah fondasi dari soft skill yang justru lebih menunjang tingkat kesuksesan seseorang dalam hidupnya. Kemampuan teknis hebat yang tidak diiringi karakter yang baik adalah percuma. Ia tidak akan mampu bekerja sama dan berempati kepada rekannya. Selain itu, penggunaan ilmu pengetahuan yang dilakukan oleh karakter yang tidak baik akan menghadirkan konsekuensi yang buruk pula.Pendidikan karakter adalah segala upaya untuk mengarahkan, melatih, memupuk nilai-nilai baik agar menumbuhkan kepribadian yang baik, bijak, sehingga dapat memberikan kontribusi yang positif kepada lingkungan dan masyarakat luas.

Definisi tersebut sejalan dengan pendapat Megawangi (dalam Kesuma, 2013, hlm.5) yang berpendapat bahwa pendidikan karakter adalah sebuah usaha sadar untuk mendidik anak-anak agar dapat mengambil keputusan yang bijak dan mempraktikannya dalam kehidupan sehari-hari, sehingga dapat memberikan kontribusi positif terhadap lingkungannya.Pendidikan adalah berbagai upaya untuk mewujudkan pembelajaran agar peserta didik dapat secara aktif belajar dan mengembangkan potensi dirinya menjadi lebih baik dari segi kecerdasan, pengetahuan, kepribadian, dsb.

Dunia intersubjektif ikut andil dalam menentukan kehidupan anak-anak remaja dalam lingkungan masyarakat. Artinya, tabiat, sifat, dan perilaku anak-anak remaja dipengaruhi oleh budaya dalam lingkungannya. Budaya tersebut termanifestasi dalam mengelola dan memengaruhi pembawaan sifat dan perilaku para remaja. Hal ini sejalan dengan pendapat Ritzer (dalam Susiati, et.al, 2021), dunia intersubjektif menciptakan suatu realitas sosial yang dipaksa oleh struktur budaya dan lingkungan sosial ciptaan leluhur mereka sebelumnya (hal. 35)

Improving the quality of education is one of the most important elements in efforts to improve the quality of human resources, especially in the effectiveness og the teaching and learning process. The effectiveness in the teaching and learning process can be created if the instructor can utilize the learning methods that are suitable to the conditions of the students and the material that will be presented (Susiati, et.al, 2019).

Kecerdasan intelektual tanpa diikuti dengan karakter atau akhlak yang mulia maka tidak akan ada gunanya. Maka dari itu, karakter atau akhlak adalah sesuatu yang sangat mendasar dan saling melengkapi. Masyarakat yang tidak berkarakter atau 
berakhlak mulia maka disebut sebagai manusia tidak beradab dan tidak memiliki harga atau nilai sama sekali. Oleh karena itu, maka aspek tersebut dipandang sangat penting.

Oleh karena itu, pada diri remaja diperlukan sosialisasi dan internalisasi nilai-nilai semenjak mereka masih kecil. Ritzer (2014) mengatakan bahwa syarat dan fungsi bagi terpeliharanya integritas pola nilai di dalam sistem adalah proses internalisasi dan sosialisasi (hal. 86). Susiati (2019) mengatakan bahwa manusia adalah makhluk sosial yang perkembangan jiwanya tidak ditentukan sejak lahir tetapi dibentuk oleh lingkungannya. Lingkungan manusia itulah yang disebut kebudayaan (hal. 117).

Karakter atau akhlak mulia itu harus dibangun. Sedangkan membangun akhlak mulia adalah melalui pendidikan, baik pendidikan di rumah (keluarga), di sekolah, maupun di masyarakat. Untuk membentuk karakter atau akhlak mulia memerlukan pendidikan karakter dan pendidikan agama. Maka dari itu dalam pembahasan ini akan dibahas mengenai pendidikan karakter dalam pandangan Islam.

Pendidikan merupakan pilar penting dalam perkembangan kognisi anak. Sejak dimulainya peradaban manusia disitu pulalah pendidikan muncul. Pendidikan adalah suatu runtunan dalam cara pemerolehan ilmu dan penyempurnaan diri yang dilakukan manusia secara terus menerus atau berkelanjutan. Manusia tidak luput dari keterbatasan dan kekurangan sehingga untuk melengkapi keterbatasan dan kekurangan yang dimiliki tersebut, manusia harus berproses, salah satunya melalui pemerolehan ilmu melalui pendidikan. Pendidikan yang diperoleh oleh manusia tidak hanya melalui pendidikan formal tetapi pendidikan awal yang didapatkan oleh manusia adalah melalui lingkungan keluarga dan lingkungan masyarakat (Tuasalamony et.al, 2020).

Peranan orang tua dalam membentuk suatu karakter anak sangatlah penting sebab pertama kali anak menerima sosialisasi dari lembaga keluarga. orang tua merupakan cerminan dari anak sehingga anak akan menjadi apa nantinya bergantung dari cara didikan orang tua terutama karakter khususnya dalam sikap religiusitas anak dalam bermasyarakat. Pendidikan beragama juga sangat penting diberikan kepada anak karena hal tersebut dapat menjadi bekal seorang anak dalam kehidupan bermasyarakat kelak. Peran orang tua dalam memberikan pendidikan religiusitas kepada anak sangat terlihat. Pendidikan religiusitas sangat penting bagi mereka untuk didapatkan oleh anak pada usia dini. Bagi para orang tua, dengan pendidikan agama yang diberikan kepada anak, dapat memberikan pemahaman tentang baik buruk dalam masyarakat sehingga anakanak tersebut kelak tidak terjerumus dalam hal-hal yang bersifat negatif (Buton, et.al, 2020).

Masyarakat menjadi lebih berfikir ilmiah terhadap segala tindakan khususnya dalam bidang pendidikan dan pengajaran terhadap para generasi atau para remaja. Dahulu masyarakat tidak mengutamakan pendidikan karena masyarakat menganggap bahwa berpendidikan tinggi sangat menguras harta. Selain itu, dulu banyak para remaja yang tidak melanjutkan sekolah di perguruan tinggi karena belum adanya Universitas di Kabupaten Buru. Padahal dengan mengenyam pendidikan sampai ke perguruan tinggi, jika selesai akan mengubah aspek kehidupan baik kepada diri sendiri maupun ketika berada di masyarakat (Hatuwe et.al, 2021). 


\section{METODE}

Penelitian ini merupakan jenis penelitian deskriptif kualitatif dengan menggunakan pendekatan fenomenologis. Jenis penelitian deskriptif kualitatif, yakni salah satu prosedur penelitian yang menghasilkan data deskriptif berupa ucapan atau tulisan dan perilaku orang-orang yang diamati (Bodgan dan Taylor dalam Moleong, dalam Susiati 2020).

\section{Metode dan Teknik Pengumpulan Data}

Metode pengumpulan data dalam penelitian ini adalah metode observasi. Kartono (dalam Susiati, 2020) observasi adalah studi yang disengaja dan sistematis tentang fenomena dan gejala-gejala psikis dengan jalan pengamatan dan pencatatan. Observasi diarahkan pada kegiatan memperhatikan secara akurat, mencatat fenomena yang muncul, mempertimbangkan hubungan antara aspek dalam fenomena dan dilakukan dengan cara mengamati objek kajian dalam konteksnya.

Metode ini digunakan untuk mendapatkan data lisan, yaitu nilai pendidikan karakter pada siswa SD 1 Ambeua. Teknik-teknik yang digunakan untuk melengkapi metode observasi tersebut, yaitu:

\section{Teknik Observasi Partisipasi}

Melakukan kegiatan menyadap dengan berpartisipasi dalam pembicaraan, menyimak pembicaraan. Observasi partisipasi (participant observation) adalah teknik pengumpulan data yang digunakan untuk menghimpun data penelitian melalui pengamatan dan penginderaan, peneliti benar-benar terlibat dalam keseharian responden. Sibarani (dalam Susiati, 2019) metode observasi partisipasi ialah ikut berpartisipasi dalam kegiatan yang diobservasi, dideskripsi, dan dianalisis.

Jenis teknik observasi partisipasi yang digunakan dalam penelitian ini adalah partisipasi yang moderat (moderate participation). Peneliti dalam mengumpulkan data ikut observasi partisipasi dalam beberapa kegiatan tetapi ti dak semuanya.

\section{Teknik Rekam}

Teknik ini digunakan untuk merekam peristiwa-peristiwa yang secara potensial banyak mendeskripsikan perilaku yang berpendidikan karakter.

3. Teknik Catat

Dari hasil rekaman, data-data berupa nilai-nilai pendidikan karakter dari responden dicatat, selanjutnya diseleksi dan diidentifikasi berdasarkan jenis pendidikan karakter tersebut.

\section{Sumber dan Jenis Data}

Sumber data dalam penelitian ini adalah siswa SDN 1 Ambeua. Jenis data dalam penelitian ini adalah nilai-nilai yang terkandung dalam pendidikan karakter pada siswa SDN 1 Ambeua 


\section{Teknis Analisi Data}

Penelitian kualitatif memungkinkan dilakukan analisis data pada waktu peneliti berada di lapangan maupun setelah kembali dari lapangan. Pada penelitian ini, analisis data dilaksanakan bersamaan dengan proses pengumpulan data. Adapun langkahlangkah analisis penelitian ini adalah sebagai berikut Penyeleksian Data, Pengklasifikasian Data, Penganalisisan Data, dan Penyimpulan Hasil Analisis.

\section{PEMBAHASAN}

Pendidikan karakter yang diterapkan kepada siswa SDN 1 Ambeua terdiri dari tiga ranah, yakni pengetahuan moral, perasaan moral, dan tindakan moral. Teori yang digunakan dalam penentuan penerapan pendidikan karakter ini adalah teori Lickona dan Amirulloh (2015).

1. Pengetahuan Moral (Moral Knowledge)

Pengetahuan moral adalah kemampuan individu untuk mengetahui, memahami, mempertimbangkan, membedakan, menginterpretasikan macam-macam moral yang harus diterapkan dan yang harus ditanggalkan. Pengetahuan moral terdiri dari enam komponen yang meliputi:

a. Kesadaran Moral, merupakan kesadaran untuk memperhatikan dan melaksanakan moral yang ada di sekitarnya.

b. Pengetahuan Nilai Moral, kemampuan untuk memahami nilai moral dalam berbagai situasi.

c. Memahami Sudut Pandang Lain, adalah kemampuan untuk menghargai dan merasakan pendapat orang lain.

d. Penalaran Moral, kemampuan untuk memahami, mempertimbangkan dan membedakan makna bermoral.

e. Keberanian Mengambil Keputusan, yaitu kemampuan untuk tidak ragu menentukan pilihan yang tepat saat mengalami dilema moral.

f. Pengenalan Diri (Self Knowledge), mampu mengetahui dan memahami perilaku sendiri serta dapat mengevaluasinya dengan jujur.

\section{Perasaan Moral (Moral Feeling)}

Perasaan moral adalah kemampuan untuk merasa harus selalu melakukan tindakan moral yang sesuai dengan norma dan merasa bersalah jika melakukan perbuatan yang tidak sesuai dengan norma (berbuat jahat). Perasaan ini juga terdiri dari enam komponen, yaitu:

a. Mendengarkan Hati Nurani, yaitu perasaan moral naf mendorong seseorang untuk melakukan tindakan sesuai dengan hati nurani dalam sisi kognitif dan sisi emosional. Sepintar-pintarnya manusia, kelebihannya adalah tetap memperhatikan 
emosi dan tidak buta terhadap sesuatu yang objektif jika dibandingkan dengan kecerdasan buatan.

b. Harga Diri (self esteem), yakni memiliki kesadaran untuk menjaga harkat dan martabat berdasarkan nilai yang luhur.

c. Empati, memiliki kepekaan (mampu turut merasakan) penderitaan orang lain.

d. Cinta Kebaikan, kemampuan untuk merasa suka dan senang ketika melakukan kebaikan.

e. Kontrol Diri, kemampuan untuk mengendalikan emosi berlebih, baik saat marah ataupun terlalu senang (euforia).

f. Rendah Hati (humility), berarti tidak merasakan rasa keunggulan yang berlebih, dapat tetap terbuka terhadap perbaikan kesalahan dan mengatasi rasa sombong namun tetap percaya diri.

\section{Tindakan Moral}

Mampu bergerak dan melakukan tindakan nyata moral yang sesuai dengan norma, hingga mencegah perbuatan yang tidak sesuai dengan norma kebaikan lingkungan. Tindakan moral terdiri menjadi tiga komponen utama, yakni:

a. Kompetensi (competence), merupakan kemampuan untuk mengubah perasaan moral menjadi tindakan moral yang efektif.

b. Keinginan (will), kemampuan untuk kuat dan bertahan melakukan apa yang seharusnya dilakukan berdasarkan pengetahuan dan perasaan moral.

c. Kebiasaan, adalah kemampuan untuk melakukan sesuatu secara konsisten dan berulang-ulang hingga telah terbiasa dan terasa lebih ringan untuk dilakukan secara terus-menerus.

Nilai-Nilai Pendidikan Karakter pada Siswa SDN 1 Ambeua

1. Religius; Sikap dan perilaku yang patuh dalam melaksanakan ajaran agama yang dianut, toleran dan hidup rukun dengan pemeluk agama lain.

2. Jujur; Perilaku yang selalu berupaya untuk menjadi orang yang sesuai dan menetapi apa yang dilakukan baik dalam perkataan, tindakan, maupun pekerjaan.

3. Toleransi; Sikap dan perilaku yang menghargai perbedaan ras, agama, etnis, pendapat, tindakan yang berbeda.

4. Disiplin; Tindakan yang berperilaku tertib dan patuh pada ketentuan dan peraturan yang berlaku. 
5. Kerja Keras; Perilaku yang menunjukkan upaya sungguh-sungguh dalam mengatasi hambatan belajar dan tugas, serta menyelesaikannya dengan sebaikbaiknya.

6. Kreatif; Berpikir dan bekerja dengan menghasilkan cara baru atau unik dari yang telah ada/dimiliki.

7. Mandiri; Sikap dan perilaku yang tidak bergantung pada orang Iain saja.

8. Demokrasi; Cara berpikir, bersikap dan bertindak yang mempertimbangkan hak dan kewajiban dirinya dan orang banyak.

9. Rasa Ingin Tahu; Selalu berupaya untuk mengetahui lebih dalam dan meluas dari sesuatu yang dilihat, didengar dan dipelajari secara umum.

10. Semangat Kebangsaan; Berpikir, bertindak dan berwawasan yang menempatkan kepentingan bangsa dan negara di atas kepentingan diri dan kelompoknya.

11. Cinta Tanah Air; Berpikir, bersikap dan bertindak yang menunjukkan kesetiaan, kepedulian, dan penghargaan terhadap segala aspek bangsa dan negara.

12. Menghargai Prestasi; Mampu mendorong diri untuk menghasilkan sesuatu yang berguna bagi masyarakat dan mengakui, serta menghargai keberhasilan orang lain.

13. Bersahabat/Komunikatif; Tindakan yang memperlihatkan rasa senang untuk bergaul, berbicara, dan bekerja sama dengan orang lain.

14. Cinta Damai; Perilaku, sikap, perkataan, dan tindakan yang membuat orang lain merasa senang dan damai atas kehadiran individu tersebut.

15. Gemar Membaca; Kebiasaan yang selalu memberikan waktu untuk membaca dan berbagi bacaan yang bermanfaat dan memberikan kebajikan bagi dirinya.

16. Peduli Lingkungan; Selalu berupaya untuk menjaga dan melestarikan lingkungan di sekitarnya, termasuk menjaga, mencegah dan memperbaiki tatanan alam di sekitar.

17. Peduli Sosial; Sikap dan tindakan yang selalu ingin menolong dan membantu orang Iain dan masyarakat umum yang membutuhkan.

18. Tanggung Jawab; Selalu melaksanakan dan menyelesaikan tugas dan kewajiban diri, masyarakat, lingkungan, negara, dan Tuhan YME.

\section{PENUTUP}

Berdasarkan hasil penelitian dalam pembahasan sebelumnya, dapat disimpulkan beberapa hal yang menjadi temuan dalam penelitian ini terkait nilai-nilai pendidikan karakter pada siswa SDN 1 Ambeua, yakni pengetahuan moral, meliputi kesadaran moral; pengetahuan nilai moral; memahami sudut pandang orang lain; penalaran moral; keberanian mengambil keputusan; pengenalan diri (Self Knowledge). Perasaan Moral meliputi mendengarkan hati nurani; harga diri (self esteem); empati; cinta kebaikan; 
kontrol diri; rendah hati (humility). Tindakan moral meliputi kompetensi (competence); keinginan (will); kebiasaan.

\section{DAFTAR PUSTAKA}

Ritzer, G. (2014). Teori Sosiologi Modern. Terjemahan. Jakarta: Kencana Prenadamedia Group.

Susiati, S., Masniati, A., Tuasalamony, K., Hatuwe, R. S. M., Tahir, S. Z. B., Tenriawali, A. Y., \& Marasabessy, R. N. (2020). MEMBANGUN KETAHANAN RELEGIUS ANAK MELALUI ACTIVE PARENTAL INVOLVEMENT. Jurnal Islam Nusantara, 4(1), 111-125.

Susiati, \& Taufik. (2019). Nilai Pembentuk Karakter Masyarakat Wakatobi Melalui Kabhanti Wa Leja. Jurnal Totobuang, 7(1), 117-137.

Susiati, S., Iye, R., \& Suherman, L. O. A. (2019). Hot Potatoes Multimedia Applications in Evaluation of Indonesian Learning In SMP Students in Buru District. ELS Journal on Interdisciplinary Studies in Humanities, 2(4), 556-570.

Susiati, S., Masniati, A., \& Iye, R. (2021). Kearifan Lokal Dalam Perilaku Sosial Remaja Di Desa Waimiting Kabupaten Buru. Sang Pencerah: Jurnal Ilmiah Universitas Muhammadiyah Buton, 7(1), 8-23.

Susiati, S., Tenriawali, A. Y., Nursin, N., Nacikit, J., \& Mukadar, S. (2020). NILAI EDUKASI DALAM NOVEL PARTIKEL KARYA DEWI LESTARI:(The Value of Education in Particle Novels by Dewi Lestari). Uniqbu Journal of Social Sciences, 1(3), 176-183.

Susiati, S. (2020). Nilai Budaya Suku Bajo Sampela Dalam Film The Mirror Never Lies Karya Kamila Andini.

Susiati, S., Tenriawali, A. Y., Nursin, N., Nacikit, J., \& Mukadar, S. (2020). NILAI EDUKASI DALAM NOVEL PARTIKEL KARYA DEWI LESTARI:(The Value of Education in Particle Novels by Dewi Lestari). Uniqbu Journal of Social Sciences, 1(3), 176-183.

Tuasalamony, K., Hatuwe, R. S. M., Susiati, S., Masniati, A., \& Marasabessy, R. N. (2020). PENGEMBANGAN PENDIDIKAN KARAKTER DI SEKOLAH DASAR NEGERI 5 NAMLEA. Pedagogy, 7(2), 81-91.

Hatuwe, Rahma Satya Masna., Tuasalamony, Kurniati., Susiati, Susiati, Masniati, Andi., dan Yusuf, Salma. (2021). MODERNISASI TERHADAP PERUBAHAN SOSIAL MASYARAKAT DESA NAMLEA KABUPATEN BURU. Nusantara: Jurnal Ilmu Pengetahuan Sosial, 8(1), 84-96

Susiati, S. (2020). The Concept Of Togetherness In The Films" Aisyah Biarkan Kami Bersaudara" By Herwin Novianto.

Susiati, S. (2020). Eksistensi Manusia Dalam Film" Aisyah Biarkan Kami Bersaudara" Karya Herwin Novianto.

Nurhayati, N., \& Said, I. (2019). Emosi Verbal Suku Bajo Sampela. Sosial Budaya, 16(2), 114-126. 
Susiati, Y. T. Risman Iye. A. Kesantunan Imperatif Bahasa Indonesia Suku Bajo Sampela: Balai Pembinaan dan Pengembangan Bahasa. 2018. Kongres Bahasa Indonesia (No. 12, pp. 1-6). Report.

Susiati, S. (2020). Makian Bahasa Wakatobi Dialek Kaledupa. 